Journal of Finance - Marketing http://jfm.ufm.edu.vn

\title{
THE IMPACT OF CREDIT RISK ON THE PERFORMANCE OF VIETNAMESE COMMERCIAL BANKS
}

\section{Nguyen Thanh Dat ${ }^{1 \star}$, Thi Thi My Duyen ${ }^{1}$ \& Le Hong Nga ${ }^{1}$}

${ }^{1}$ Bac Lieu University

\begin{tabular}{ll} 
ARTICLE INFO & ABSTRACT \\
\hline $\begin{array}{l}\text { DOI: } \\
\text { 10.52932/jfm.vi63.164 }\end{array}$ & $\begin{array}{l}\text { The study surveyed } 30 \text { joint-stock commercial banks in Vietnam from } \\
2007 \text { to 2019, the article uses a regression model with panel data through } \\
\text { the Hausman test to choose the appropriate estimation method to test the } \\
\text { impact of the NPL ratio factors on the performance of commercial banks. } \\
\text { The study found that credit risk indicators have a significant positive } \\
\text { effect on the profitability of banks. Besides, there is a positive relationship } \\
\text { between bank size and bank performance. From the research results, the } \\
\text { author proposes several ideas to limit the impact of credit risk on the } \\
\text { January 18, } 2021\end{array}$ \\
$\begin{array}{l}\text { Accepted: } \\
\text { March 8, 2021 } \\
\begin{array}{l}\text { Published: } \\
\text { June 25, 2021 }\end{array}\end{array}$ \\
$\begin{array}{l}\text { Keywords: } \\
\begin{array}{l}\text { Performance } \\
\text { efficiency, } \\
\text { Commercial banks, } \\
\text { Credit risk. }\end{array}\end{array}$ \\
\hline
\end{tabular}

${ }^{*}$ Corresponding author:

Email: nthdatblu@gmail.com 
Tạp chí Nghiên cứu Tài chính - Marketing

http://jfm.ufm.edu.vn

\section{TÁC ĐộNG CỦA RỦI RO TÍN DỤNG ĐẾN HIỆU QUẢ HOẠT ĐộNG CỦA CÁC NGÂN HÀNG THƯƠNG MẠI VIỆT NAM}

\section{Nguyễn Thành Đạt ${ }^{1 *}$, Thi Thị Mỹ Duyên ${ }^{1}$ \& Lê Hồng Nga ${ }^{1}$}

${ }^{1}$ Trường Đại học Bạc Liêu

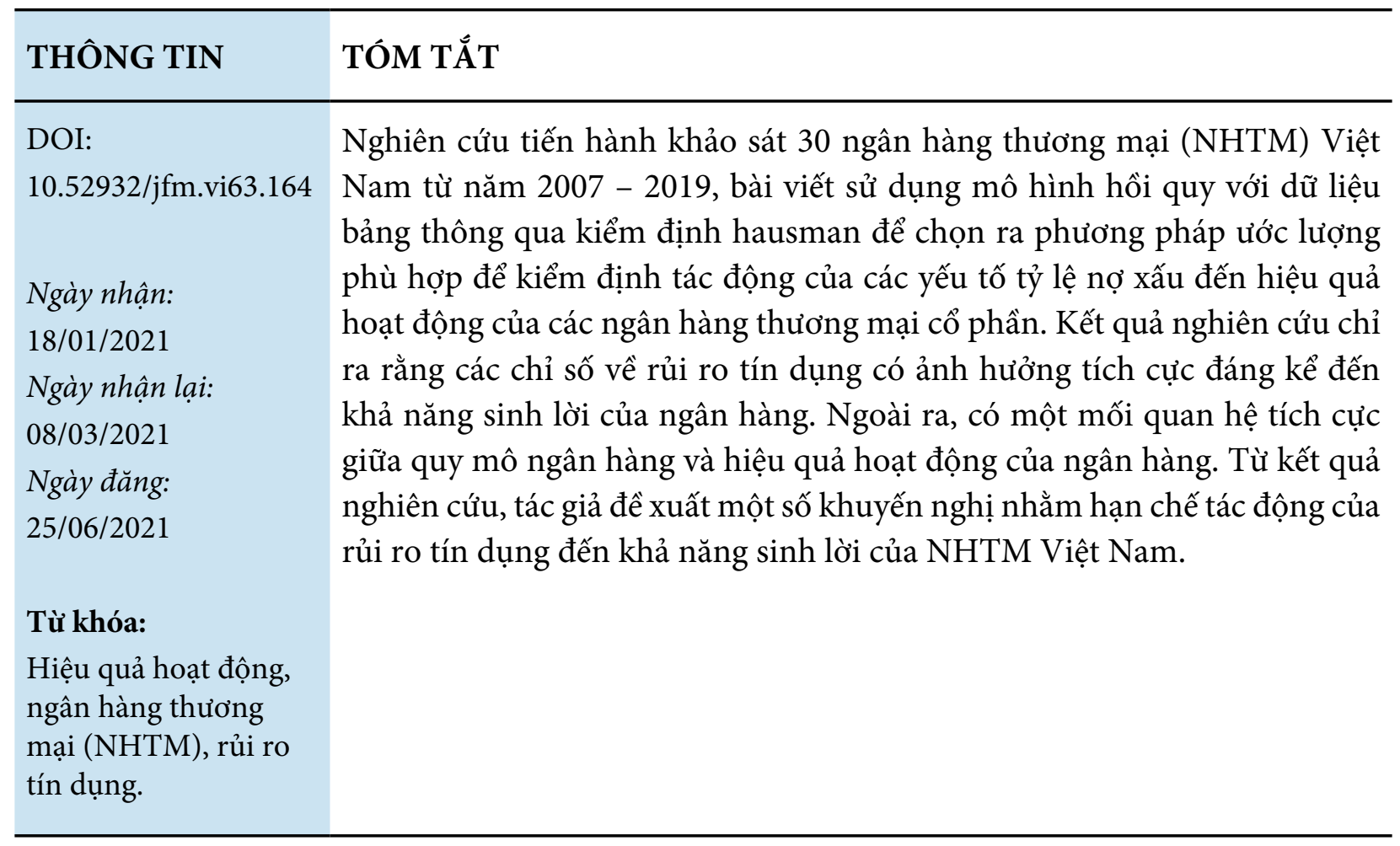

\section{Giới thiệu}

Hệ thống ngân hàng đóng vai trò quan trọng đối với sự phát triển của nền kinh tế, là cầu nối cho vốn được luân chuyển từ nơi thừa vốn đến nơi có nhu câu sử dụng. Do đó, sự ổn định của ngành ngân hàng được xem

*Tác giả liên hệ:

Email: nthdatblu@gmail.com là yếu tố then chốt đối với sự phát triển của nền kinh tế. Các ngân hàng phải chịu nhiêu rủi ro có thể ảnh hưởng đến hoạt động của họ và khả năng sinh lời (Alshatti, 2015). Theo Koch và MacDonald (2014), những rủi ro này có thể được phân loại thành rủi ro tín dụng, rủi ro thị trường, rủi ro hoạt động, rủi ro thanh khoản, rủi ro pháp lý và rủi ro danh nghĩa. Mỗi yếu tố trong số chúng có thể ảnh hưởng tiêu cực đến vốn chủ sở hửu, giá trị thị trường, nợ phải trả và hoạt động tài chính của 
các ngân hàng. Ekinci \& Poyraz (2019) tuyên bố rằng một trong những hoạt động chính tạo ra thu nhập cho các ngân hàng chính là hoạt động tín dụng, nhưng hoạt động tín dụng lại là một trong những rủi ro lớn nhất mà các ngân hàng phải đối mặt.

Theo Basle Committee on Banking Supervision và Bank for International Settlements (2000), rủi ro tín dụng được định nghĩa là khả năng một khách hàng vay nợ nhưng không thực hiện các cam kết đã thỏa thuận từ trước với ngân hàng. Boffey và Robson (1995) khẳng định loại rủi ro này là rủi ro đáng kể nhất ảnh hưởng đến hoạt động của các ngân hàng, trong khi Saeed và Zahid (2016) định nghĩa giá trị tín dụng là chỉ số quan trọng về sức khỏe tài chính và sự lành mạnh của các ngân hàng. Nghiên cứu của Nair và Fissha (2010) chỉ ra rằng tỷ lệ nợ xấu cao trong các NHTM làm ảnh hưởng tiêu cực đến ngành ngân hàng. Tỷ lệ nợ xấu cao, một chỉ số về rủi ro tín dụng, có khả năng giảm hiệu quả tài chính của ngân hàng. Ngân hàng càng phải đối mặt với rủi ro tín dụng nhiều hơn, thì khả năng xảy ra khủng hoảng tài chính ngân hàng cao hơn. Nói cách khác, mức độ cao của rủi ro tín dụng có thể dẫn đến mức rủi ro vỡ nợ cao, điêuu này sẽ gây ảnh hưởng cho ngân hàng người gửi tiền (Bizuayehu, 2015). Bên cạnh đó trong thời gian qua, mặc dù các NHTM đã có những nỗ lực lớn trong việc xử lý nợ xấu nhưng tỷ lệ nợ xấu vẫn ở mức cao. Theo báo cáo tài chính hợp nhất đã công bố của các ngân hàng đến cuối tháng 6 , nợ xấu của một số ngân hàng có xu hướng tăng lên so với Quý I như VCB, VPB, STB, VBB, LPB, ACB, cho thấy các ngân hàng hoạt động kém hiệu quả trong thời kỳ suy thoái và điều này sẽ làm tăng áp lực lên chất lượng tín dụng trong ngắn hạn. Tính đến hết Quý I năm 2020, các ngân hàng đã cơ cấu lại thời hạn trả nợ cho trên 12.000 khách hàng với dư nợ 13,5 nghìn tỷ đông, và đến giữa tháng 05/2020, con số dư nợ được cơ cấu lại đã gân 138 nghìn tỷ đông. Với tình hình nợ xấu gia tăng, hoạt động mua bán nợ với cồng ty Quản lý tài sản (VAMC) được dự báo sẽ diễn ra sôi động hơn và với khối lượng lớn hơn trước. Tính đến thời điểm đầu năm 2020, trên toàn hệ thống đã có 13 ngân hàng thực hiện tất toán toàn bộ trái phiếu VAMC (Hồ Hữu Tín \& Lê Đức Quang Tú, 2020). Đây cũng là thời điểm tròn 5 năm kết thúc kỳ hạn của trái phiếu đặc biệt do VAMC phát hành. Điều đó có nghĩa là các NHTM sẽ nhận lại những khoản nợ xấu không xử lý được sau khi đã bán sang VAMC. Điều này dẫn đến nợ xấu nội bản của các ngân hàng tăng lên. Do đó, điều cần thiết là các ngân hàng phải áp dụng một cách tiếp cận hiệu quả để quản lý và giảm thiểu rủi ro tín dụng mà họ phải chịu. Cho nên tác giả nghiên cứu vấn đề này nhằm đánh giá tác động của rủi ro tín dụng đối với hoạt động kinh doanh thương mại các ngân hàng ở Việt Nam và sau đó đưa ra để xuất cho các nhà quản lý ngân hàng nhằm hạn chế rủi ro tín dụng hiệu quả hơn.

\section{Cơ sở lý thuyết và phương pháp nghiên cứu}

\subsection{Cơ sở lý thuyết}

Thuyết chi phí đại diện: Lý thuyết này được giới thiệu nhằm giải thích tầm ảnh hưởng của cơ cấu sở hữu đối với lợi nhuận. Theo đó, các nhà quản lý thường thực hiện các thể chế dựa trên lợi ích của mình hơn là tối ưu hóa tài sản và lợi ích của chủ sở hữu. Một cách hiệu quả để giải quyết mâu thuẫn đại diện là sở hữu quản trị. Phương pháp này nhằm củng cố tỷ lệ sở hữu của các nhà quản lý trong công ty, giúp hài hòa lợi ích giữa nhà quản lý và công ty, buộc họ phải hành động vì lợi ích của các cổ đông. Nhìn từ góc độ này, có vẻ như các ngân hàng được sở hữu bởi cổ đông sẽ hoạt động tốt hơn các ngân hàng tương hỗ, ngân hàng hợp tác xã hay ngân hàng Chính phủ.

Thuyết phát tín hiệu: Lý thuyết này nói về những thông tin khác nhau trong nội bộ như giữa các giám đốc và các bộ phận trong công ty hay giữa các bên như các nhà đầu tử 
(Ross, 1977). Theo đó, các nhà quản lý tiếp cận được nhiều thông tin quan trọng về tình hình tài chính của công ty hơn người ngoài cuộc. Trong khi đó, các nhà đầu tư bên ngoài lại phải đối mặt với nhiêuu thông tin có thể khiến họ bị hiểu lầm khi đánh giá cơ hội đầu tư. Do đó, những biến động về cơ cấu vốn sẽ phát tín hiệu cho các bên ngoài nắm bắt được hiệu quả hoạt động của công ty.

Thuyết chi phí giao dịch: Khái niệm chi phí giao dịch lần đâu tiên được Coase (1995) đề cập trong bài của mình với tựa đê "Bản chất của doanh nghiệp". Chi phí giao dịch bao gồm thời gian và chi phí đàm phán, soạn thảo, và thực thi các giao dịch hay hợp đông. Thuyết này sau đó được Foss (1996) phát triển với bản chất là khi đầu tư công nghệ sẽ làm giảm chi phí sản xuất và dẫn đến giá bán giảm như vậy chi phí giao dịch sẽ giảm cho người mua, đó là khách hàng mua được sản phẩm giá rẻ nhưng chất lượng là không đổi. Bên cạnh đó, Chen \& Zhu (2004) cũng đã nghiên cứu công nghệ và năng suất, khi sử dụng công nghệ sẽ làm năng suất tăng và chi phí giao dịch sẽ giảm.

\section{Các nghiên cứu trước}

Rủi ro tín dụng được coi là loại rủi ro quan trọng nhất đối với các NHTM. Bởi quản lý rủi ro tín dụng hiệu quả, ngân hàng không chỉ nâng cao tính bền vững và lợi nhuận kinh doanh của họ mà còn đóng góp vào sự ổn định kinh tế và phân phối vốn hiệu quả trong nền kinh tế (Psillaki và cộng sự, 2010). Một loạt các nghiên cứu về mối quan hệ giữa rủi ro tín dụng và hoạt động của các ngân hàng đã được thực hiện trên toàn thế giới. Trong khi một số nghiên cứu ủng hộ tác động tích cực của rủi ro tín dụng đối với lợi nhuận của các ngân hàng, những người khác cho rằng có mối quan hệ nghịch đảo giữa chúng.

Theo Basle Committee on Banking Supervision và Bank for International Settlements (2000), rủi ro tín dụng được định nghĩa là khả năng một khách hàng vay nợ nhưng không thực hiện các cam kết đã thỏa thuận từ trước với ngân hàng. Boffey và Robson (1995) cho rằng rủi ro tín dụng là rủi ro lớn nhất ảnh hưởng đến hiệu quả hoạt động của ngân hàng; đông thời, Saeed và Zahid (2016) cũng xem giá trị tín dụng là một chỉ số quan trọng cho sức khỏe tài chính của các ngân hàng. Nair và Fissha (2010) cũng đã nhận thấy các NHTM có hệ số nợ xấu cao và hệ số này có tác động nghịch biến đến ngành công nghiệp. Hệ số nợ xấu, một biến đo lường rủi ro tín dụng, có thể làm giảm hiệu quả hoạt động tài chính của các ngân hàng. Một ngân hàng càng gặp nhiều rủi ro tín dụng thì khả năng ngân hàng đó đối mặt với khủng hoảng tài chính càng cao. Nói cách khác, mức rủi ro tín dụng cao có thể dẫn đến mức rủi ro vỡ nợ cao, cuối cùng sẽ làm nguy hại đến các khách hàng gửi tiền của ngân hàng (Bizuayehu, 2015). Vì thế, các ngân hàng thực sự cần một phương pháp quản lý và hạn chế rủi ro tín dụng hiệu quả. Việc quản lý rủi ro tín dụng hiệu quả không những giúp các ngân hàng cải thiện được tính bền vững và khả năng sinh lời trong hoạt động của mình mà còn đóng góp cho việc phân bổ vốn hiệu quả và sự ổn định của nền kinh tế (Psillaki và cộng sự, 2010). Hiệu quả sử dụng vốn (CEE), hiệu quả sử dụng nguôn nhân lực (HCE) và cơ cấu vốn (SCE) có ảnh hưởng tích cực đến hiệu quả hoạt động tài chính của các ngân hàng (Lê Hồng Nga \& Nguyễn Thành Đạt, 2021).

Hiện nay, trên thế giới đã có nhiều nghiên cứu phân tích mối quan hệ giữa rủi ro tín dụng và hiệu quả hoạt động của ngân hàng. Trong khi một số nghiên cứu tìm ra ảnh hưởng đông biến của rủi ro tín dụng đến khả năng sinh lời của các ngân hàng, một số nghiên cứu khác lại cho thấy mối quan hệ nghịch biến giữa rủi ro tín dụng và khả năng sinh lời của ngân hàng. Boahene và cộng sự (2012) đã kiểm định mối quan hệ giữa rủi ro tín dụng 
và lợi nhuận tại 06 NHTM ở Ghana giai đoạn 05 năm từ 2005 đến 2009. Tác giả sử dụng 03 biến đo lường rủi ro tín dụng, gồm: hệ số nợ xấu, hệ số khoanh nợ ròng (net chargeoff rate) và hệ số lợi nhuận trước khi trích lập dự phòng/tổng dư nợ; trong khi đó, tỷ suất sinh lợi trên vốn chủ sở hữu (ROE) được sử dụng làm biến phụ thuộc. Kết quả hôi quy từ mô hình dũ liệu bảng chỉ ra rủi ro tín dụng có mối quan hệ đồng biến với hiệu quả hoạt động của ngân hàng, cho thấy các ngân hàng ở Ghana có khả năng sinh lời cao mặc dù chịu rủi ro tín dụng cao. Alshatti (2015) sử dụng mô hình dũ liệu bảng để kiểm định liệu các biến đo lường rủi ro tín dụng có mối tương quan với hiệu quả hoạt động (được đo bằng ROA và ROE) của các NHTM ở Jordan hay không. Kết quả cho thấy hệ số nợ xấu/tổng dư nợ có ảnh hưởng đông biến đến khả năng sinh lời của các ngân hàng. Tương tự, Saeed và Zahid (2016) thu thập dũ̃ liệu từ 05 NHTM lớn ở Vương Quốc Anh từ năm 2007 đến 2015, sử dụng mô hình hồi quy tuyến tính để ước lượng tác động của rủi ro tín dụng được đo bởi nợ xấu đến khả năng sinh lời (được đo bởi $R O A$ và $R O E$ ); kết quả là tất cả các biến rủi ro tín dụng đều có tác động đông biến đến hiệu quả hoạt động tài chính của các ngân hàng. Kết quả của các nghiên cứu trên giống với kết quả nghiên cứu của Afriyie và Akotey (2012); Abiola và Olausi (2014). Gần đây, Le (2017) đã sử dụng mẫu dũ liệu gồm 40 ngân hàng trong giai đoạn 11 năm để nghiên cứu các yếu tố ảnh hưởng đến lợi nhuận của NHTM tại Việt Nam bằng phương pháp GMM (generalized method of moments). Nghiên cứu sử dụng hệ số dự phòng rủi ro tín dụng/tổng dư nợ là biến độc lập của mô hình; kết quả chỉ ra biến đo lường rủi ro tín dụng có mối quan hệ đồng biến với khả năng sinh lời của các NHTM Việt Nam. Ekinci và Poyraz (2019) kiểm định mối quan hệ nêu trên với 26 ngân hàng tại Thổ Nhĩ Kỳ từ 2005 đến 2017, sử dụng hệ số nợ quá hạn/tổng dư nợ để đo lường rủi ro tín dụng, sử dụng ROA và $\mathrm{ROE}$ là biến phụ thuộc. Ước lượng từ mô hình dữ liệu bảng chỉ ra mối quan hệ nghịch biến giữa rủi ro tín dụng và khả năng sinh lời. Tương tự, Hamza (2017) đã sử dụng ROA và $\mathrm{ROE}$ để đo lường hiệu quả hoạt động khi phân tích đối với các ngân hàng tại Pakistan, kết quả nghiên cứu cho thấy hệ số dự phòng rủi ro tín dụng và tỷ số nợ xấu có mối quan hệ nghịch biến với hiệu quả hoạt động ngân hàng. Phân tích 20 NHTM tại Uganda trong giai đoạn 2006 - 2015, Serwadda (2018) đã sử dụng mô hình dữ liệu bảng để kiểm định giả thiết quản trị rủi ro tín dụng có tác động đến lợi nhuận ngân hàng hay không; kết quả tác giả đã tìm ra hệ số ROA của các NHTM chịu tác động nghịch biến bởi nợ xấu, điêu này hàm ý rằng nợ xấu có thể ảnh hưởng lớn đến chất lượng tài sản của các NHTM ở Uganda. Liên quan đến ngành ngân hàng tại Trung Quốc, Isanzu (2017) đã chỉ ra quan hệ nghịch biến giữa hệ số nợ xấu và $\mathrm{ROA}$ của các ngân hàng, cho thấy rủi ro tín dụng cao sẽ có thể làm giảm hiệu quả hoạt động tài chính của các ngân hàng thương mại Trung Quốc. Kết quả này cũng tương đồng với kết quả thực nghiệm được thực hiện bởi Kodithuwakku (2015) tại Sri Lanka. Sử dụng mô hình partial least squares (PLS), Gadzo và cộng sự (2019) tìm thấy rủi ro tín dụng (đại diện bởi hệ số nợ xấu và hệ số an toàn vốn tối thiểu $\mathrm{CAR}$ ) có mối quan hệ nghịch biến với tỷ suất sinh lợi trên vốn chủ sở hữu $(\mathrm{ROE})$ và tỷ lệ thu nhập lãi cận biên (NIM) của các ngân hàng tại Ghana. Bên cạnh đó, kết quả nghiên cứu chỉ ra rằng rủi ro hoạt động có tác động nghịch biến đến khả năng sinh lời của các ngân hàng. Nguyễn Thành Đạt (2020) cũng cho thấy có mối quan hệ ngược chiều giữa vốn ngân hàng đến khả năng sinh lời và cùng chiều với rủi ro tín dụng. Bên cạnh đó, nghiên cứu còn cho thấy các yếu tố ảnh hưởng đến khả năng sinh lời và rủi ro tín dụng ngân hàng bao gồm tăng 
trưởng tín dụng, quy mô ngân hàng, GDP và lạm phát. Do còn tôn tại nhiều sự không tương đông trong kết quả nghiên cứu trên thế giới về mối quan hệ giữa rủi ro tín dụng và khả năng sinh lời của các ngân hàng, nghiên cứu này hướng đến việc phân tích tác động của rủi ro tín dụng đến hiệu quả hoạt động của các NHTM tại Việt Nam, từ đó đưa ra các kiến nghị, đề xuất nhằm nâng cao hiệu quả quản trị rủi ro tín dụng cho các ngân hàng.

Bảng 1. Các biến trong mô hình

\begin{tabular}{|c|c|c|c|}
\hline Tên biến & Mô tả & Công thức & Dấu kì vọng \\
\hline ROA & Tỷ suất sinh lợi trên tổng tài sản & Lợi nhuận sau thuế/ Tổng tài sản & + \\
\hline ROE & $\begin{array}{l}\text { Tỷ suất sinh lợi trên vốn chủ } \\
\text { sở hưu }\end{array}$ & $\begin{array}{l}\text { Lợi nhuận sau thuế/ Tổng vốn chủ } \\
\text { sở hữu }\end{array}$ & + \\
\hline NIM & Tỷ lệ thu nhập lãi cận biên & $\begin{array}{l}\text { Thu nhập lãi ròng/ Tổng tài sản có } \\
\text { sinh lãi }\end{array}$ & + \\
\hline NPLR & Hệ số nợ xấu & Nợ xấu/ Tổng dư nợ & + \\
\hline LDR & $\begin{array}{l}\text { Hệ số dư nợ trên tiên gửi của } \\
\text { khách hàng }\end{array}$ & $\begin{array}{l}\text { Tổng dư nợ/ Tổng tiên gửi của } \\
\text { khách hàng }\end{array}$ & + \\
\hline LLPR & Hệ số dự phòng rủi ro tín dụng & $\begin{array}{l}\text { Dự phòng rủi ro tín dụng/Nợ } \\
\text { quá hạn }\end{array}$ & + \\
\hline SIZE & Quy mô ngân hàng & Logarit tổng tài sản & + \\
\hline GDP & Tăng trưởng kinh tế & Tỷ lệ tăng trưởng & + \\
\hline INF & Lạm phát & Tỷ lệ lạm phát & + \\
\hline
\end{tabular}

\subsection{Phương pháp nghiên cứu}

\section{Dũ liệu nghiên cứu}

Mẫu nghiên cứu sau khi loại trừ các ngân hàng không công bố đây đủ và các ngân hàng đã sáp nhập, bao gồm 30 ngân hàng với tổng cộng 390 quan sát theo năm cho dữ liệu bảng trong 13 năm từ 2007 - 2019. Dữ liệu nghiên cứu được thu thập từ báo cáo tài chính, bảng cân đối kế toán, bảng thuyết minh của các NHTM Việt Nam từ 2007 - 2019. Chỉ số GDP, lạm phát, được thu thập từ báo cáo của Tổng cục thống kê Việt Nam.

\section{Phương pháp nghiên cứu}

\section{Mô hình nghiên cứu}

Nghiên cứu được thực hiện dựa trên các nghiên cứu trước Serwadda (2018), Gadzo và cộng sự (2019), Nguyễn Thành Đạt (2020) mô hình hồi quy được trình bày tổng quát như sau:
$\mathrm{Y}_{\mathrm{it}}=\alpha+\beta \cdot$ Credit risk $_{\mathrm{it}}+\gamma \cdot$ control $_{\mathrm{it}}+\varepsilon$

Trong đó:

$\mathrm{Y}_{\mathrm{it}}$ là hiệu quả tài chính của NHTM, được đo lường bằng tỷ suất lợi nhuận trên tổng tài sản $(\mathrm{ROA})$ và tỷ suất sinh lợi trên vốn chủ sở hữu (ROE), tỷ lệ thu nhập lãi cận biên (NIM);

Credit risk ${ }_{\mathrm{it}}$ là rủi ro của ngân hàng gồm các biến NPLR, LLPR, LDR;

Control $_{i t}$ là tập hợp các biến kiểm soát;

i và $t$ đại diện cho quan sát tương ứng với NHTM thứ i trong năm $\mathrm{t}$;

$\alpha, \beta, \gamma$ lân lượt là các hệ số hôi quy; còn $\varepsilon$ là phần dứ.

Biến phụ thuộc dựa vào cách lựa chọn biến phụ thuộc từ các nghiên cứu Alshatti (2015); Ekinci \& Poyraz (2019); Saeed \& Zahid (2016); Hamza (2017); Gadzo và cộng sự (2019). Nghiên cứu sử dụng 03 biến đo lường 
khả năng sinh lợi của các NHTM, gồm: tỷ suất sinh lợi trên tổng tài sản $(\mathrm{ROA})$, tỷ suất sinh lợi trên vốn chủ sở hữu (ROE) và tỷ lệ thu nhập lãi cận biên (NIM).

Kĩ thuật hồi quy bảng được sử dụng để phân tích tác động của các biến đối với NPL. Trong nghiên cứu này tác giả sẽ lần lượt thực hiện hồi quy mô hình tác động cố định FE, và mô hình tác động ngẫu nhiên $R E$. Tiếp theo dùng kiểm định Hausman giúp lựa chọn giữa mô hình $\mathrm{FE}$ và $\mathrm{RE}$, nếu giá trị Prob của kiểm định Hausman $>\alpha=0,05$ thì bác bỏ giả thuyết $\mathrm{H}_{0}$ tức mô hình RE phù hợp, ngược lại thì FE phù hợp.

\section{Kết quả và thảo luận}

Bảng 2. Thống kê mô tả

\begin{tabular}{llllll}
\hline Tên biến & $\begin{array}{l}\text { Số } \\
\text { quan sát }\end{array}$ & $\begin{array}{l}\text { Trung } \\
\text { bình }\end{array}$ & $\begin{array}{l}\text { Độ lệch } \\
\text { chuẩn }\end{array}$ & $\begin{array}{l}\text { Giá trị } \\
\text { nhỏ nhất }\end{array}$ & $\begin{array}{l}\text { Giá trị } \\
\text { lớn nhất }\end{array}$ \\
\hline ROA & 390 & 0,068 & 0,007 & $-0,055$ & 0,059 \\
ROE & 390 & 0,088 & 0,080 & $-0,045$ & 0,362 \\
NIM & 390 & 0,032 & 0,015 & $-0,008$ & 0,154 \\
NPLR & 390 & 0,028 & 0,061 & 0,000 & 1,000 \\
LDR & 390 & 0,804 & 0,303 & 0,382 & 3,133 \\
LLPR & 390 & 0,385 & 0,439 & 0,009 & 6,308 \\
SIZE & 390 & 20,732 & 1,228 & 15,018 & 21,122 \\
GDP & 390 & 0,063 & 0,085 & 0,050 & 0,084 \\
INF & 390 & 0,078 & 0,062 & 0,006 & 0,231 \\
\hline
\end{tabular}

Bảng 2 cho thấy biến ROA có giá trị trung bình 0,068 , giá trị nhỏ nhất $-0,055$ và giá trị lớn nhất là 0,059 . Bên cạnh đó biến $\mathrm{ROE}$ và NIM có giá trị trung bình lần lượt là 0,088 và 0,032 , đồng thời giá trị nhỏ nhất và lớn nhất là $-0,045,-0,008$ và 0,362 và 0,154 .

Kết quả kiểm định Hausman để lựa chọn giữa mô hình $\mathrm{FE}$ và $\mathrm{RE}$, kết quả kiểm định cho ra giá trị (Prob $<$ Chi $2=0,021<\alpha=0,05)$; (Prob $<$ Chi $2=0,004<\alpha=0,05)$; (Prob $<$ Chi $2=0,001<\alpha=0,05)$ nên ta chấp nhận giả thuyết $\mathrm{H}_{0}$, mô hình $\mathrm{FE}$ phù hợp hơn $\mathrm{RE}$. Kết quả phân tích hôi quy theo mô hình FE được trình bày ở bảng 3. Kiểm định Breusch - Pagan cho mô hình FE cho kết quả Prob > Chi $2=1,000>\alpha=0,05$ nên mô hình không có xảy ra hiện tượng phương sai sai số thay đổi. Đông thời kiểm định tự tương quan theo Worldridge cho Prob $>$ Chi $2=0,13>\alpha=$ 0,05 nên mô hình không xảy ra hiện tượng tự tương quan. Kiểm định đa cộng tuyến hệ số tương quan VIF không có trường hợp nào vượt quá 10 . Độ lớn của các hệ số tương quan chỉ ra rằng khả năng xuất hiện đa cộng tuyến trong mô hình hôi quy là thấp (Hair và cộng sự, 2010).

Bảng 3. Kết quả mô hình tác động cố định (FEM)

\begin{tabular}{llll}
\hline TÊN BIẾN & ROA & ROE & NIM \\
\hline NPLR & $0,018^{\star}$ & $0,087^{\star}$ & 0,006 \\
& $(0,007)$ & $(0,053)$ & $(0,005)$ \\
LDR & $0,005^{\star}$ & $0,052^{\star}$ & $0,018^{\star *}$ \\
& $(0,004)$ & $(0,042)$ & $(0,009)$
\end{tabular}




\begin{tabular}{llll}
\hline TÊN BIẾN & ROA & ROE & NIM \\
\hline LLPR & 0,003 & $0,008^{* *}$ & $0,006^{*}$ \\
& $(0,002)$ & $(0,004)$ & $(0,005)$ \\
SIZE & $0,004^{* *}$ & $0,070^{* *}$ & 0,004 \\
& $(0,003)$ & $(0,032)$ & $(0,003)$ \\
GDP & $-5,412^{*}$ & $-41,735^{*}$ & $-6,432$ \\
& $(3,125)$ & $(56,387)$ & $(3,875)$ \\
INF & $-0,312$ & $-4,754$ & $-0,365$ \\
& $(0,165)$ & $(2,643)$ & $(0,352)$ \\
\hline Số quan sát & 388 & 388 & 388 \\
R bình phương & 0,260 & 0,201 & 0,243 \\
Prob $>$ F & 0,000 & 0,000 & 0,000 \\
\hline
\end{tabular}

Ghi chú: Mức ý nghĩa ${ }^{*}$ biểu thị $P<0,1$; ${ }^{* *}$ biểu thị $P<0,05$; ${ }^{* *}$ biểu thị $P<0,01$.

Như kết quả ở bảng trên ta thấy được mô hình 1 có ý nghĩa ở mức $26 \%$ điều này cho thấy các biến trong mô hình 1 giải thích được khoảng $26 \%$ của $\mathrm{ROA}$ và mô hình 3 có ý nghĩa ở mức trên $24 \%$ điêu này cho thấy các biến trong mô hình 3 giải thích được khoảng $24 \%$ của NIM, còn mô hình 2 thì mức ý nghĩa là $20 \%$ tức là các biến trong mô hình chỉ giải thích được $20 \%$ biến ROE

Kết quả nghiên cứu cho thấy hệ số nợ xấu (NPLR) có tác động đồng biến đến ROA và ROE, và có ý nghĩa thống kê ở mức $10 \%$. Điều này chỉ ra rằng sự gia tăng trong nợ xấu có thể làm tăng khả năng sinh lời của các ngân hàng. Mối quan hệ đồng biến này cũng đồng nhất với kết quả của Afriyie \& Akotey (2012); Abiola \& Olausi (2014); Alshatti (2015); Saeed \& Zahid (2016); Boahene và cộng sự (2012). Khi đối mặt với rủi ro tín dụng, các ngân hàng có thể sẽ tăng phần bù rủi ro vỡ nợ lớn hơn mức rủi ro thực tế, dẫn đến làm tăng thu nhập của họ (Boahene và cộng sự, 2012). Theo Afriyie và Akotey (2012), điều này cũng đồng nghĩa với việc ngân hàng không có một phương pháp quản trị rủi ro tín dụng hiệu quả, bởi lẽ họ chỉ đơn giản là chuyển phần bù rủi ro vỡ nợ cho khách hàng dưới hình thức tăng lãi suất cho vay.
Trong cả 03 mô hình, tham số ước lượng của hệ số dư nợ trên tiền gửi của khách hàng (LDR) mang giá trị dương và đều có ý nghĩa thống kê, kết quả này tương đông với Bizuayehu (2015), Kolapo và cộng sự (2012), cho thấy sự gia tăng trong hệ số này có thể làm tăng hiệu quả hoạt động tài chính của ngân hàng. Nói cách khác, ngân hàng càng mở rộng hoạt động tín dụng thì có xu hướng gia tăng được lợi nhuận của mình (Bizuayehu, 2015).

Ngoài ra, mối quan hệ tích cực đáng kể giữa tỷ lệ dự phòng rủi ro cho vay (LLPR) và khả năng sinh lời của các ngân hàng được tìm thấy trong mô hình (2) và (3), kết quả phù hợp với các nghiên cứu của Gizaw và cộng sự (2015), Nwanna và Oguezue (2017). Điều này trái với quan điểm lý thuyết của Serwadda (2018). Theo Gizaw và cộng sự (2015), mối quan hệ tích cực giữa LLPR và hiệu quả hoạt động của ngân hàng có thể gợi ý rằng các nhà quản lý ngân hàng coi hoạt động kinh doanh cho vay trong lĩnh vực ngân hàng là rủi ro mặc dù có lợi nhuận. Trong khi đó, Anandarajan và cộng sự (2003) khẳng định có mối quan hệ tích cực của hệ số mô tả rằng dự phòng rủi ro cho vay có thể được sử dụng để thao túng thu nhập, nghĩa là cho vay dự phòng tổn thất sẽ 
được giảm để quản lý thu nhập khi thu nhập của ngân hàng giảm.

Biến quy mô ngân hàng (SIZE) dương và có ý nghĩa thống kê, chứng tỏ rằng ngân hàng có quy mô càng lớn thì khả năng sinh lời càng cao. Nói cách khác, các ngân hàng có được lợi thế về chi phí (Ekinci \& Poyraz, 2019).

\section{Kết luận và khuyến nghị}

\subsection{Kết luận}

Các nghiên cứu trước đây về mối quan hệ giữa rủi ro tín dụng và hiệu quả hoạt động của các ngân hàng cho ra nhiêu kết quả khác nhau, nghiên cứu này nhằm phân tích tác động của rủi ro tín dụng đối với khả năng sinh lời của các ngân hàng thương mại cổ phần tại Việt Nam. Kết quả nghiên cứu cho thấy rằng các chỉ số về rủi ro tín dụng có mối quan hệ tích cực và có ý nghĩa thống kê với khả năng sinh lời của các ngân hàng, điều này cho thấy các NHTM ở Việt Nam có xu hướng hưởng lợi từ rủi ro tín dụng bằng việc cho vay lãi suất cao. Ngoài ra, các ngân hàng có thể tận dụng lợi thế của quy mô kinh tế để cải thiện hiệu quả tài chính của họ.

\subsection{Khuyến nghị}

Kết quả nghiên cứu chỉ ra rằng rủi ro tín dụng có mối quan hệ đồng biến và có ý nghĩa thống kê với khả năng sinh lời của các ngân hàng. Cho nên cần kiểm soát chặt chẽ hoạt động tín dụng, cần có các biện pháp tích cực xử lý nợ xấu bằng cách trích lập dự phòng, thu hồi nợ từ khách hàng để gia tăng chất lượng tài sản cho vay, từ đó tối ưu hóa hiệu quả hoạt động, góp phân nâng cao sức cạnh tranh của ngân hàng.

Bên cạnh đó cần kiểm soát tốt các chi phí, cải thiện năng suất và mở rộng quy mô nguồn lực đểnâng cao sức cạnh tranh của ngân hàng.

Ngoài ra cần quan tâm đến công tác huy động vốn bằng các chính sách: Triển khai chính sách thu hút khách hàng như: Marketing, lãi suất, nâng cao chất lượng phục vụ, dịch vụ ngân hàng cung cấp và mở rộng hoạt động kinh doanh. Khi ngân hàng huy động được tiền gửi cũng góp phân làm giảm tỷ lệ vốn chủ sở hữu trên tổng tài sản, góp phần cải thiện hiệu quả hoạt động.

\section{TÀI LIỆU THAM KHẢO}

Abiola, I., \& Olausi, A. S. (2014). The impact of credit risk management on the commercial banks performance in Nigeria. International Journal of Management and Sustainability, 3(5), 295-306.

Afriyie, H. O., \& Akotey, J. O. (2012). Credit risk management and profitability of selected rural banks in Ghana. Working Paper, Catholic University College of Ghana.

Alshatti, A. S. (2015). The effect of credit risk management on financial performance of the Jordanian commercial banks. Investment management and financial innovations, 12(1-2), 338-345.

Anandarajan, A., Hasan, I., \& Lozano-Vivas, A. (2003). The role of loan loss provisions in earnings management, capital management, and signaling: The Spanish experience. Advances in International Accounting, 16, 45-65.

Basle Committee on Banking Supervision, \& Bank for International Settlements (2000). Principles for the management of credit risk: Bank for International Settlements.

Bizuayehu, M. (2015). The impact of credit risk on financial performance of banks in Ethiopia. Unpublished M.Sc Thesis, Addis Ababa University.

Boahene, S. H., Dasah, J., \& Agyei, S. K. (2012). Credit risk and profitability of selected banks in Ghana. Research Journal of finance and accounting, 3(7), 6-14.

Boffey, R., \& Robson, G. N. (1995). Bank credit risk management. Managerial Finance, 21(1), 66. 
Chen, Y., \& Zhu, J. (2004). Measuring information technology's indirect impact on firm performance. Information Technology and Management, 5(1), 9-22.

Coase, R. H. (1995). The nature of the firm. Essential readings in economics, 37-54. London: Palgrave.

Ekinci, R., \& Poyraz, G. (2019). The effect of credit risk on financial performance of deposit banks in Turkey. Procedia Computer Science, 158, 979-987.

Foss, K. (1996). Transaction costs and technological development: the case of the Danish fruit and vegetable industry. Research Policy, 25(4), 531-547.

Gadzo, S. G., Kportorgbi, H. K., \& Gatsi, J. G. (2019). Credit risk and operational risk on financial performance of universal banks in Ghana: A partial least squared structural equation model (PLS SEM) approach. Cogent Economics \& Finance, 7(1), 1589406.

Gizaw, M., Kebede, M., \& Selvaraj, S. (2015). The impact of credit risk on profitability performance of commercial banks in Ethiopia. African Journal of Business Management, 9(2), 59-66.

Hair, J. F., Black, W. C., Babin, B. J., \& Anderson, R. E. (2010). Multivariate Data Analysis (7 $7^{\text {th }}$ ed.). Harlow, UK: Pearson.

Hamza, S. M. (2017). Impact of credit risk management on banks performance: A case study in Pakistan banks. European Journal of Business and Management, 9(1), 57-64.

Isanzu, J. S. (2017). The impact of credit risk on financial performance of Chinese banks. Journal of International Business Research and Marketing, 2(3).

Koch, T. W., \& MacDonald, S. S. (2014). Bank management: Nelson Education.

Kodithuwakku, S. (2015). Impact of credit risk management on the performance of commercial banks in Sri Lanka. International Journal of Scientific Research and Innovative Technology, 2(7), 1-6.

Kolapo, T. F., Ayeni, R. K., \& Oke, M. O. (2012). Credit risk and commercial banks'performance in nigeria: a panel model approach. Australian journal of business and management research, 2(2), 31.

Le, T. (2017). The determinants of commercial bank profitability in Vietnam. Available at SSRN: https:// ssrn.com/abstract=3048571. doi:10.2139/ssrn. 3048571

Lê Hồng Nga \& Nguyễn Thành Đạt (2021). Tác động của vốn trí tuệ đến hiệu quả hoạt động của các ngân hàng thương mại tại Việt Nam. Tạp Chí Nghiên cứu Tài chính - Marketing, 1(61). https://doi. org/10.52932/jfm.v1i61.66

Nair, A., \& Fissha, A. (2010). Rural banking: The case of rural and community banks in Ghana. Agriculture and Rural Development Discussion Paper No. 48. The World Bank.

Nguyễn Thành Đạt (2020). Nguôn vốn ngân hàng ảnh hưởng đến khả năng sinh lời và rủi ro tín dụng của ngân hàng thương mại cổ phẩn Việt Nam. Tạp Chí Nghiên cứu Tài chính - Marketing, (52), 12-21. https://doi.org/10.52932/jfm.vi52.127

Nwanna, I. O., \& Oguezue, F. C. (2017). Effect of credit management on profitability of deposit money banks in Nigeria. IIARD International Journal of Banking and Finance Research, 3(2), 137-161.

Psillaki, M., Tsolas, I. E., \& Margaritis, D. (2010). Evaluation of credit risk based on firm performance. European journal of operational research, 201(3), 873-881.

Ross, S. A. (1977). The determination of financial structure: the incentive-signalling approach. The Bell Journal of Economics, 8(1), 23-40.

Saeed, M., \& Zahid, N. (2016). The impact of credit risk on profitability of the commercial banks. Journal of Business \& Financial Affairs, 5(2), 2167-0234.

Serwadda, I. (2018). Impact of credit risk management systems on the financial performance of commercial banks in Uganda. Acta Universitatis Agriculturae et Silviculturae Mendelianae Brunensis, 66(6), 1627-1635. 